\title{
POLÍTICAS PÚBLICAS DE ACESSIBILIDADE VOLTADA AOS IDOSOS: O CASO BRASILEIRO
}

\author{
N. G. da Silva Filho' ${ }^{1}$ R. C. Magagnin ${ }^{2}$ \\ 1, 2 PPGARQ, UNESP, Bauru, Av. Eng. Luiz Edmundo Carrijo Coube, 14-01, Bauru-SP \\ nivaldo.geroncio.filho@gmail.com ${ }^{1}$,magagnin@faac.unesp.br ${ }^{2}$
}

\begin{abstract}
Resumo: O Brasil encontra-se num processo de transição de faixa etária bastante acentuada, ou seja, a mudança no comportamento da população está se caracterizando de um estado jovem para um estado idoso. Tal mudança deve ser vista com certa preocupaçáo, sobretudo ao olhar das políticas públicas, desde o governo federal, passando pelos estados e com maior responsabilidade pelo município. Neste sentindo, observa-se que deve ser dada maior ênfase à parcela idosa da população. Estes problemas, embora imperceptíveis para a maioria das pessoas que não têm mobilidade reduzida, limita de forma contundente a população idosa, pois, o que se observa na prática é a precariedade ou ausência de normas e leis que possam de fato favorecer o segmento idoso. Assim sendo, este trabalho tem como objetivo discutir alguns pontos das políticas públicas brasileiras voltadas à acessibilidade e verificar se elas estão incorporando a questão dos idosos no espaço urbano. A metodologia adotada foi extraída de uma revisão bibliográfica nacional e internacional a respeito do assunto. As análises e os resultados demonstram que são necessárias melhorias significativas nessas infraestruturas.
\end{abstract}

Palavras-chave: Políticas públicas, Mobilidade urbana, Acessibilidade, Idoso.

Abstract: Brazil is in a transition process a very marked age, that is, the change in the behavior of the population is being characterized from a young state to an elderly state. Such a change must be viewed with some concern, especially when looking at public policies, from the federal government, through states and with greater responsibility for the municipality. In this sense, it should be noted that the older part of the population should be given greater emphasis. These problems, although imperceptible to the majority of people who do not have reduced mobility, severely limit the elderly population, since what is observed in practice is the precariousness or absence of norms and laws that may actually favor the elderly segment. Thus, this paper aims to discuss some aspects of Brazilian public policies aimed at accessibility and to verify if they are incorporating the issue of the elderly in the urban space. The methodology adopted was taken from a national and international literature review on the subject. Analyzes and results demonstrate that significant improvements are needed in these infrastructures.

Keywords: Public policies, Urban mobility, Accessibility, Elderly, Urban space. 


\section{Introduçáo}

O envelhecimento populacional e o processo de urbanização das cidades são duas tendências mundiais que, em conjunto, representam as maiores forças que moldam o século XXI [1]. Ao mesmo tempo em que as cidades crescem, tem aumentado, cada vez mais, o seu contingente de residentes com 60 anos ou mais.

O número de pessoas com idade de 60 anos ou mais dobrará, proporcionalmente, passando de 11\%, em 2006, para 22\%, em 2050 [1]. Assim, é possível afirmar que pela primeira vez na história da humanidade haverá mais idosos que crianças (com idade 0 -14 anos) na população. Países em desenvolvimento estáo envelhecendo em uma velocidade muito maior que a dos países desenvolvidos. Em cinco décadas, pouco mais de $80 \%$ dos idosos do mundo viverão em países em desenvolvimento, comparativamente com 60\% em 2006 [1]. A Figura 1 sintetiza este argumento.

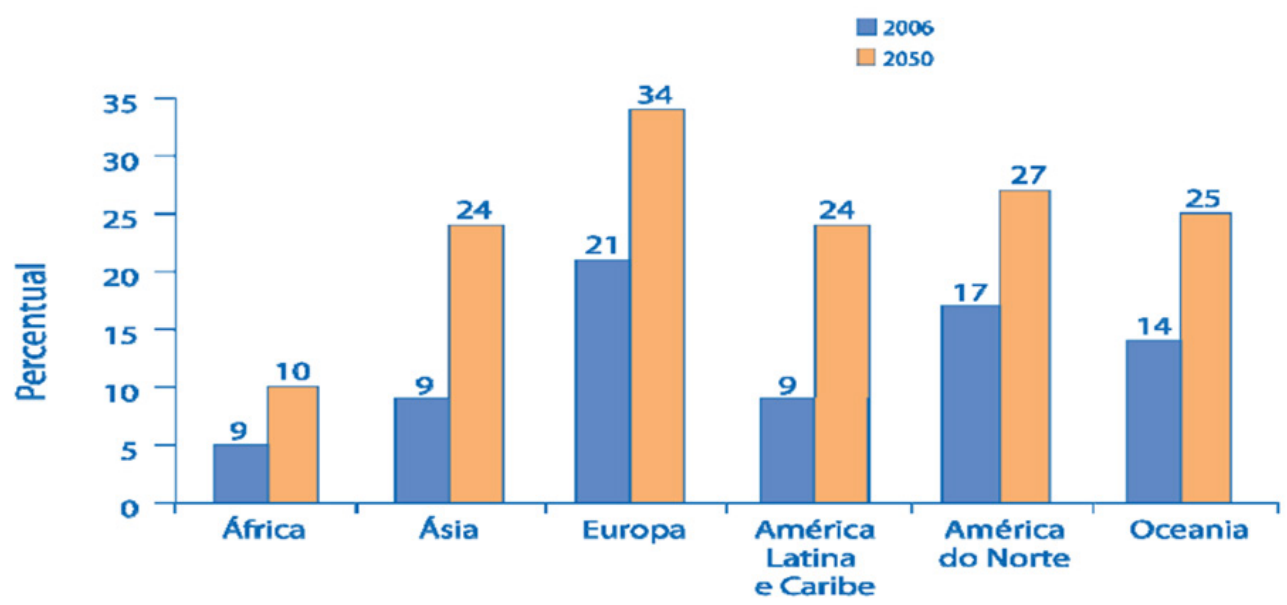

Figura 1 - Percentual de distribuição da população mundial (\%) de 60 anos ou mais por regiáo, 2006 e 2050 [1].

O número de megacidades, isto é, aquelas com 10 milhóes de habitantes ou mais, aumentou dez vezes, passando de dois para 20, ao longo do século XX [1]. Elas respondiam por 9\% da população urbana do mundo em 2005. As projeções indicam que a população urbana continuará a aumentar nas próximas décadas, especialmente em cidades com menos de cinco milhóes de habitantes em 2030 [1]. 


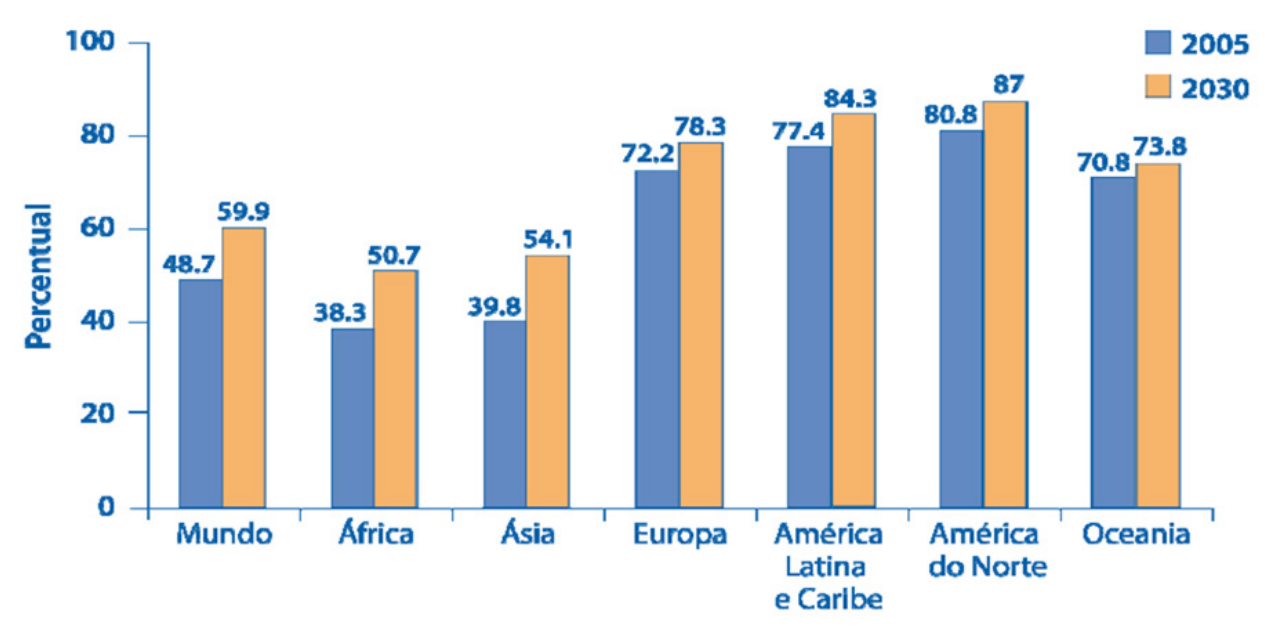

Figura 2 - Percentual da população urbana em grandes centros, 2005 e 2030 [1].

No tocante ao processo de envelhecimento pode-se observar que o Brasil estava em um claro processo de envelhecimento, tendo ultrapassado etapas iniciais do processo de transição epidemiológica e mesmo até mesmo atingindo seu estágio final [2,3]. Aproximadamente na década de 1950, as características demográficas brasileiras apontavam a existência de uma população muito jovem, com altas taxas de fertilidade e mortalidade. A partir de 1960, teve início um processo de redução das taxas de fertilidade, para o País, considerando no seu conjunto, as taxas de fertilidade diminuíram aproximadamente 30\%, no período de 1970 e 1980, queda esta que se verificou em todas as regiôes do Brasil. No entanto, mesmo com este crescimento, a sociedade vive em um meio projetado para pessoas jovens, que não apresentam nenhuma dificuldade de locomoção ou mobilidade reduzida [2].

É comum encontrar em muitas cidades passeios irregulares ou mesmo com buracos, praças com barreiras físicas e técnicas, sem deixar de citar as dificuldades de acessos a bancos, farmácias, supermercados, hospitais e áreas de lazer. Este conjunto de barreiras pode dificultar ou mesmo impedir que um cidadão utilize de maneira plena o ambiente onde ele vive. Dentre as pessoas com desvantagens, os idosos aparecem como um público representativo e que, muitas vezes, se veem confinados em suas casas, privando-se de sua participação no convívio social [4]. No Brasil o processo de envelhecimento vem chamando a atenção de pesquisadores de diversos campos de atuação (Engenheiros, Gerontólogos, Fisioterapeutas, Geógrafos, Sociólogos).

No caso específico dos urbanistas, de modo geral, tal processo é visto com bastante preocupação, pois as infraestruturas urbanas, sobretudo no caso brasileiro não são adequadas ao segmento idoso. Neste sentido, faz-se necessário reelaborar açóes públicas e investir na mudança da representação social da pessoa idosa, abandonando a concepção da passividade desta população. Dedicar atenção especial a reforçar a proteção social em casos de extrema vulnerabilidade, nas quais persistem dificuldades de acesso a direitos fundamentais como a moradia, a saúde e a segurança social. 


\section{A questáo da mobilidade reduzida: o idoso e suas limitaçóes}

Para fins de definição, a pessoa com mobilidade reduzida pode ser classificada em permanente ou parcial. No caso dos idosos, esta redução pode ser caracterizada de forma gradativa, pois o envelhecimento trata-se de um processo natural do ser humano.

Nesse bojo da discussão é importante frisar que o termo acessibilidade pode ser definido como sendo um atributo essencial do ambiente que garante a melhoria da qualidade de vida das pessoas [5]. Deve estar presente nos espaços, no meio físico, no transporte, na informação e comunicação, inclusive nos sistemas e tecnologias da informação e comunicação, bem como em outros serviços e instalaçóes abertos ao público ou de uso público, tanto na cidade como no campo.

Outra definição a essa terminologia diz que a acessibilidade é um atributo que está associado ao indivíduo [6] ou a acessibilidade pode ser definida como a possibilidade e condição de alcance, percepção e entendimento para a utilização com segurança e autonomia de edificaçôes, espaço, mobiliário, equipamento urbano e elementos [7].

Os idosos participam do trânsito de diversas maneiras: como pedestres, passageiros, ciclistas, motociclistas ou motoristas. No entanto, junto com as crianças, eles constituem um grupo de risco, ou seja, tem probabilidade maior a acidentes de trânsito [8]. O termo "mobilidade" está na ordem do dia, seja na imprensa, nas agendas públicas ou no meio científico e tem se aplicado a abordagens e contextos diversos [9]. Ele está relacionado com as seguintes definições: acesso e acessibilidade, também com diferentes possibilidades de uso.

Consenso há no fato de que mobilidade é condição para as pessoas acessarem os diferentes bens e serviços de uma cidade. No entanto, para a concretizaçáo deste direito muitas vezes é necessário à eliminação de barreiras arquitetônicas e urbanísticas, nas edificaçôes, nos transportes, como também a eliminação de barreiras nas comunicaçóes. Mas, infelizmente não é incomum identificar nos ambientes urbanos, em especial nas calçadas a presença de buracos, a falta de rampas, escadas sem opção de elevador ou plataforma de elevação, elevadores sem a escrita em braile e sem sinalização sonora, locais com a ausência de piso tátil, o que dificulta e até impede o acesso da pessoa com deficiência e mobilidade reduzida ao meio físico.

Diversos autores $[2,10,11]$ identificaram que as principais limitaçôes fisiológicas que afetam a mobilidade da pessoa idosa estão relacionadas a:

1. Perda da visão: perda da acuidade visual, ou seja, nitidez com que se veem objetos, diminuição da visão periférica e do campo visual, menor tolerância à luminosidade, confusão na compreensão de contrastes e dificuldade em adaptar-se ao escuro. Com a visão prejudicada, a pessoa perde o equilíbrio, pois os olhos são órgãos determinantes para o controle da postura; 
2. Perda da audição: aumentam as anormalidades do órgáo auditivo, dificultando a percepção dos barulhos e ruídos, e contribuindo para a perda de equilíbrio da pessoa prejudicando sua orientação de espaço;

3. Dificuldade de locomoção: enfraquecimento dos ossos com a perda de cálcio, problemas nas articulações reduzindo a flexibilidade, e a perda do equilíbrio afetado pelos órgãos da visão, audição e pela redução da força muscular;

4. Aumento do tempo de reação: conforme o grau de complexidade da tarefa a ser executada, o idoso apresenta um maior tempo de reação em decorrência do envelhecimento;

5. Declínio da velocidade de julgamento: dificuldade de julgar a distância a que está do veículo em relação à velocidade desenvolvida por este veículo.

Dentre os elementos que podem contribuir para a falta de acessibilidade de passeios e calçadas destacam-se os seguintes elementos: Largura efetiva da calçada; Tipo de Piso; Rampas de acesso; Travessia segura; Inclinação e Conservação das calçadas [2].

\section{Passeios e calçadas: $o$ idoso na condiçáo de pedestre}

Os passeios, calçadas e travessias compóem a infraestrutura viária dos pedestres, portanto, interferem no deslocamento dos idosos. Assim é de fundamental que toda esta infraestrutura esteja sempre em condiçôes adequadas para o trânsito das pessoas. A calçada, por definição, é parte integrante da via, normalmente segregada e em nível diferente, é reservada ao trânsito de pedestres e, quando possível, à implantação de mobiliário, sinalização, vegetação e outros fins [7]. A largura mínima é de 1,30 metros que seria o espaço suficiente para a pessoa idosa que necessite fazer uso de um material auxiliar para seu deslocamento. A Figura 3 apresenta as dimensôes referenciais para deslocamento de pessoas em pé nas mais diversas características. 

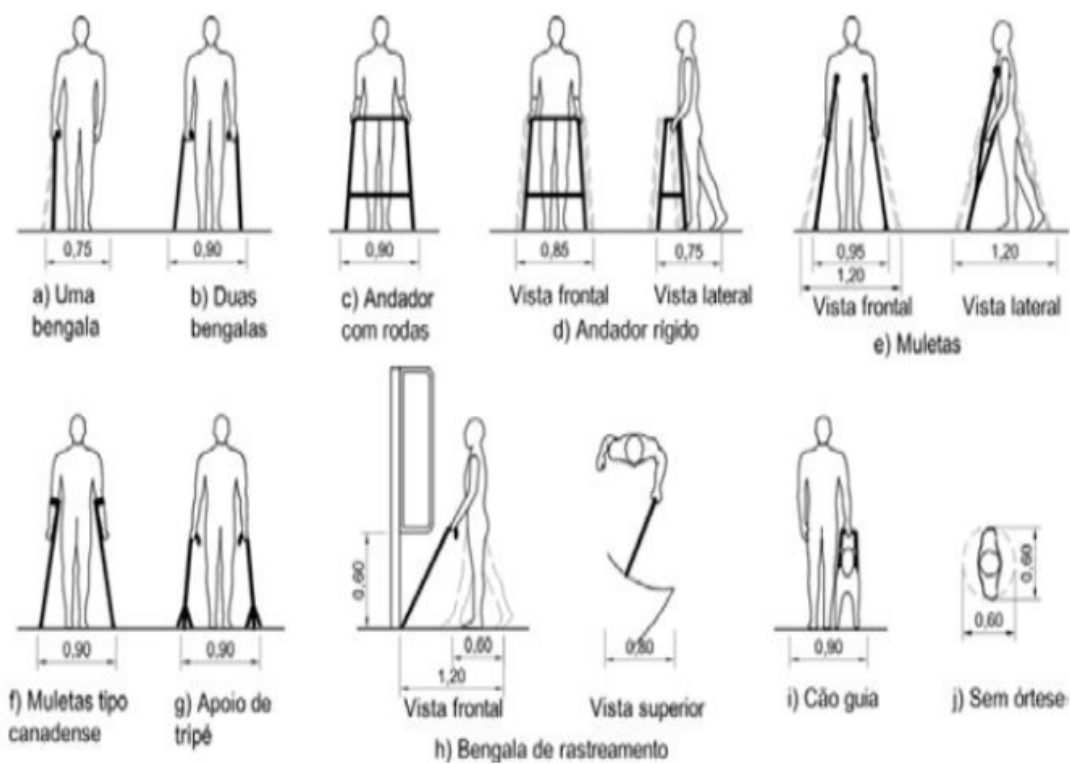

Figura 3 - Dimensôes referenciais de pedestres em relação à calçada [7].

\section{As políticas públicas e o espaço da cidade}

As políticas públicas voltadas para a promoção, proteção e defesa dos direitos das pessoas idosas são de responsabilidade das esferas federal e estadual e a implantação destas políticas cabem aos governos municipais. [2]

O artigo 182 da Constituição Federal, que trata da política de desenvolvimento urbano, executada pelo Poder Público municipal, conforme diretrizes gerais fixadas em lei, tem por objetivo ordenar o pleno desenvolvimento das funçóes sociais da cidade e garantir o bem-estar de seus habitantes.

A lei de $\mathrm{n}^{\circ} 8.842$, de 4 de janeiro de 1994, cria, dispóe sobre a sobre a política nacional do idoso [5]. De acordo com o art. $1^{\circ}$ dessa lei, a política nacional do idoso tem por objetivo assegurar os direitos sociais do idoso, criando condiçóes para promover sua autonomia, integraçáo e participaçáo efetiva na sociedade. São consideradas idosas as pessoas acima de sessenta anos de idade.

Art. $3^{\circ}$. A política nacional do idoso reger-se-á pelos seguintes princípios:

I - a família, a sociedade e o estado têm o dever de assegurar ao idoso todos os direitos da cidadania, garantindo sua participação na comunidade, defendendo sua dignidade, bem-estar e o direito à vida;

II - o processo de envelhecimento diz respeito à sociedade em geral, devendo ser objeto de conhecimento e informaçáo para todos;

Art. $4^{\circ}$. Constituem diretrizes da política nacional do idoso: I - viabilização de formas alternativas de participação, ocupação e convívio do idoso, que proporcionem sua integração às demais geraçôes; II - participação do idoso, através de suas organizaçóes representativas, na formulação, implementação e avaliação das políticas, planos, programas e projetos a serem desenvolvidos. [2] . 
Em 2000, a Lei no 10.098 , em seu artigo $1^{\circ}$, estabelecia normas gerais e critérios básicos para a promoção da acessibilidade das pessoas portadoras de deficiência ou com mobilidade reduzida, mediante a supressão de barreiras e de obstáculos nas vias e espaços públicos, no mobiliário urbano, na construção e reforma de edifícios e nos meios de transporte e de comunicação.

Contudo, foi apenas em 2015, com a promulgação da Lei 13.146, que a palavra "idoso" foi inserida em seu contexto, assim como outros grupos com mobilidade reduzida. Uma cidade amiga do idoso, em consonância com a Lei acima, adapta suas estruturas e serviços para que estes sejam acessíveis e promovam a inclusão de idosos com diferentes necessidades e graus de capacidade.

Muitos aspectos do ambiente urbano e dos serviços sinalizam às características de uma cidade amiga do idoso. Respeito e inclusão social se refletem na acessibilidade de prédios e espaços públicos e na gama de oportunidades que a cidade oferece para os idosos em termos de participação social. A Figura 4 ilustra, de forma mais detalhada, estas características.

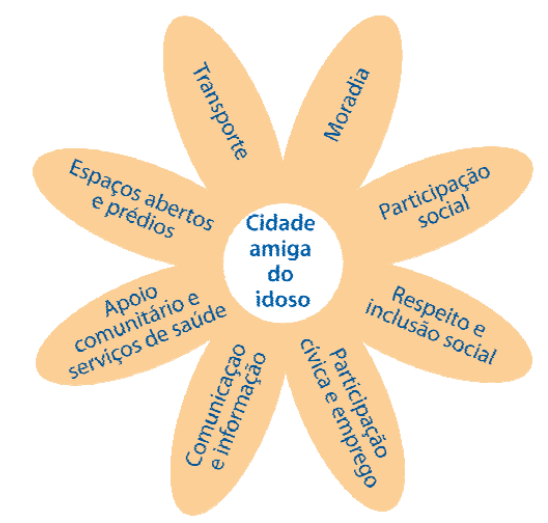

Figura 4 - Tópicos relacionados ao estatuto da Cidade Amiga do Idoso [1].

\section{Conclusóes}

A Constituição Federal brasileira define que o direito de ir e vir deve ser assegurado a todos os cidadãos, neste sentido, devem ser eliminadas todas as barreiras físicas que impeçam o acesso das pessoas com deficiência e mobilidade reduzida aos prédios públicos, aos estabelecimentos comerciais, de ensino, praças, parques, cinemas e tantos outros. Diante desta premissa, pode-se afirmar que a promoção da acessibilidade faz parte do processo de inclusão social não só de pessoas com deficiência, mas para todos que permanentemente ou temporariamente têm mobilidade limitada, categorias estas que incluem crianças, idosos, mulheres grávidas e pessoas obesas [13].

O Brasil possui um número significativo de legislaçóes e normas técnicas sobre esta temática, no entanto o idoso não tem a garantia de ter espaços plenamente acessíveis. As cidades brasileiras ainda possuem inúmeros espaços públicos e privados com restrição total ou parcial de mobilidade, o que impede o direito de ir e vir assegurado na lei [13]. 
A esfera federal tem se preocupado em propor leis e políticas públicas para implantar a acessibilidade nos municípios, entretanto, os municípios ainda não adotaram medidas efetivas para favorecer a acessibilidade na cidade, principalmente nos espaços de uso público.

\section{Agradecimentos}

A Coordenação de Aperfeiçoamento de Pessoal de Nível Superior (CAPES), pelo Projeto de Pós-doutorado, junto a Faculdade de Arquitetura, Artes e Comunicação (FAAC) e Programa de Pós-graduação em Arquitetura e Urbanismo (PPGARQ) da UNESP - Bauru.

\section{Referências}

[1] OMS - ORGANIZAÇÃO MUNDIAL DE SAÚDE. Envelhecimento ativo: uma política de saúde. Tradução de Suzana Gontijo. Brasília: Opas, 2008. 60 p.

[2] SILVA FILHO, N. G. Índice de qualidade da mobilidade urbana a pé para pessoas idosas (IQMUI) / Tese (Doutorado) Nivaldo Gerôncio da Silva Filho. São Carlos: UFSCar, 2016. 166 p.

[3] Guia global: cidade amiga do idoso. Brasília: OMS, 2008. KALACHE, A. Envelhecimento populacional no Brasil: uma realidade nova. Cadernos de Saúde Pública, v. 3, n. 3, p. 217-220, 1987.

[4] PRADO, A. R. A. Acessibilidade e Desenho Universal. Versão atualizada do texto publicado nos Anais do $3^{\circ}$ Congresso Paulista de Geriatria e Gerontologia - GERP’ 2003, Sociedade Brasileira de Geriatria e Gerontologia SBGG/SP, Santos, 2003.

[5] Guia de Políticas, Programas e Projetos do Governo Federal. Compromisso Nacional para o Envelhecimento Ativo, - Brasil. Neusa Pivatto Müller (Org.). Brasília: Secretaria de Direitos Humanos da Presidência da República, 2015.

[6] BRASIL. Ministério das Cidades. Mobilidade e desenvolvimento urbano / Ministério das Cidades, Secretaria de Transporte e da Mobilidade Urbana. Gestão Integrada da Mobilidade Urbana, Brasília: MCidades, 2006.

[7] ABNT. NBR 9050. Acessibilidade a edificaçóes, mobiliário, espaços e equipamentos urbanos. Associação Brasileira de Normas Técnicas, São Paulo: ABNT. 2015.

[8] ROZESTRATEN, R. J. A. O idoso no trânsito. Jornal da ABRAMET. São Paulo, Psicologia do trânsito, p. 8, 1993.

[9] BARRETO, K. M. L. Envelhecimento, mobilidade urbana e saúde: um estudo da populaçáo idosa. Tese (Doutorado em Saúde Pública). 177 p. Centro de Pesquisas Aggeu Magalhães, Fundação Oswaldo Cruz. Recife. 2012.

[10] MICHELETTO, T. M. G. P. O risco do idoso pedestre nas vias urbanas. NT 219, Companhia de Engenharia de Tráfego de São Paulo, São Paulo. 2011.

[11] SANT'ANNA, R. M. Mobilidade e segurança no trânsito da populaçáo idosa: um estudo descritivo sobre a percepçáo de pedestres idosos e de especialistas em engenharia de tráfego. Tese (Doutorado em Engenharia de Transportes). COPPE, UFRJ, Rio de Janeiro. 2006.

[12] BRASIL. Ministério das Cidades. Mobilidade e Política Urbana: Subsídios para uma Gestão Integrada. Secretaria Nacional de Transporte e da Mobilidade Urbana. Brasília. 2004. Disponível em: <http://www.cidades.gov.br/ media/ MobilidadeePoliticaUrbana.pdf>. Acesso em: 15 abr. 2016.

[13] MAGAGNIN, Renata Cardoso; PRADO, Mariana Delbonis do; VANDERLEI, C. B.. The municipal urban accessibility policy in a medium-sized city: the case of Bauru - Brazil. In: XVIII Congreso Panamericano de Ingenieria de Transito, Transporte y Logísitca, 2014, Santander - Espanha. XVIII Congreso Panamericano de Ingenieria de Transito, Transporte y Logísitca. Santander: PANAM, 2014. v. 1. p. 01-15. 